\title{
Conflicting Roles of Nickel in Controlling Cathode Performance in Lithium Ion Batteries
}

\author{
Meng Gu, ${ }^{\dagger}$ Ilias Belharouak, ${ }^{\ddagger}$ Arda Genc, ${ }^{\S}$ Zhiguo Wang, ${ }^{\perp}$ Dapeng Wang, ${ }^{\ddagger}, \|$ Khalil Amine, ${ }^{\ddagger}$ Fei Gao, ${ }^{\perp}$ \\ Guangwen Zhou," Suntharampillai Thevuthasan, ${ }^{\dagger}$ Donald R. Baer, ${ }^{\dagger}$ Ji-Guang Zhang, \\ Nigel D. Browning, ${ }^{\perp}$ Jun Liu, ${ }^{\perp}$ and Chongmin Wang ${ }^{*}, \dagger$
}

${ }^{\dagger}$ Environmental Molecular Science Laboratory, ${ }^{\perp}$ Fundamental and Computational Science Directorate, and ${ }^{\#}$ Energy and Environmental Directorate, Pacific Northwest National Laboratory, 902 Battelle Boulevard, Richland, Washington 99352, United States

${ }^{\ddagger}$ Chemical Sciences and Engineering Division, Argonne National Laboratory, 9700 South Cass Avenue, Argonne, Illinois 60439, United States

${ }^{\S}$ FEI Company, 5350 NE Dawson Creek Drive, Hillsboro, Oregon 97124, United States

"Department of Mechanical Engineering, Binghamton University, State University of New York, Binghamton, New York 13902, United States

\section{Supporting Information}

ABSTRACT: A variety of approaches are being made to enhance the performance of lithium ion batteries. Incorporating multivalence transition-metal ions into metal oxide cathodes has been identified as an essential approach to achieve the necessary high voltage and high capacity. However, the fundamental mechanism that limits their power rate and cycling stability remains unclear. The power rate strongly depends on the lithium ion drift speed in the cathode. Crystallographically, these transition-metal-based cathodes frequently have a layered structure. In the classic wisdom, it is accepted that lithium ion travels swiftly within the layers
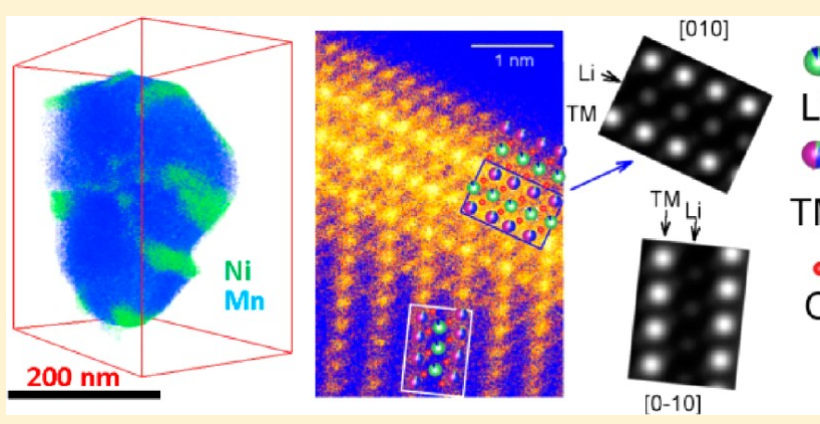
moving out/in of the cathode during the charge/discharge.

Here, we report the unexpected discovery of a thermodynamically driven, yet kinetically controlled, surface modification in the widely explored lithium nickel manganese oxide cathode material, which may inhibit the battery charge/discharge rate. We found that during cathode synthesis and processing before electrochemical cycling in the cell nickel can preferentially move along the fast diffusion channels and selectively segregate at the surface facets terminated with a mix of anions and cations. This segregation essentially can lead to a higher lithium diffusion barrier near the surface region of the particle. Therefore, it appears that the transition-metal dopant may help to provide high capacity and/or high voltage but can be located in a "wrong" location that may slow down lithium diffusion, limiting battery performance. In this circumstance, limitations in the properties of lithium ion batteries using these cathode materials can be determined more by the materials synthesis issues than by the operation within the battery itself.

KEYWORDS: Lithium ion battery, $\mathrm{Li}_{1.2} \mathrm{Ni}_{0.2} \mathrm{Mn}_{0.6} \mathrm{O}_{2}$, nickel segregation, STEM, DFT calculation, lithium diffusion barrier

\begin{abstract}
$\mathrm{L}$ ithium ion batteries have been widely used in consumer $\checkmark$ electronics and have entered the electrical vehicle market due to their high energy density. ${ }^{1-3}$ However, their power rate and cycle life still need to be improved for long-term applications. The power rate of the lithium $(\mathrm{Li})$ ion batteries strongly depends on the rate of $\mathrm{Li}^{+}$diffusion within the cathode structure. ${ }^{1,4-6}$ Significant efforts have been made to improve the power rate of $\mathrm{Li}$ ion batteries by doping cathodes to increase electronic conductivity, ${ }^{6}$ reducing the $\mathrm{Li}$ ion diffusion distances by using nanoscale particles, ${ }^{6,7}$ surface coating, ${ }^{1}$ and enhancing surface facets with $\mathrm{Li}^{+}$fast-diffusion channels. ${ }^{8}$ Lithium transition-metal oxides have been widely used as the cathode for $\mathrm{Li}$ ion batteries. They can be tailored to gain either
\end{abstract}

high voltage or high capacity by adjusting the relative ratio of different transition-metal ions and preparation conditions. ${ }^{9-20}$ For example, a layered composite based on lithium nickel manganese oxide $\mathrm{Li}_{1.2} \mathrm{Ni}_{0.2} \mathrm{Mn}_{0.6} \mathrm{O}_{2}$ (LNMO) has demonstrated a rechargeable capacity of $>250 \mathrm{mAh} / \mathrm{g}$, which is much larger than that of the conventional $\mathrm{LiCoO}_{2}$ cathode $(<140 \mathrm{mAh} /$ g). ${ }^{10,14,16,21,22}$ This category of material is featured by a layered composite structure in which the channels within the structure can act as a low-barrier path for Li ions to move during the

Received: June 15, 2012

Revised: August 22, 2012

Published: September 17, 2012 
(a)

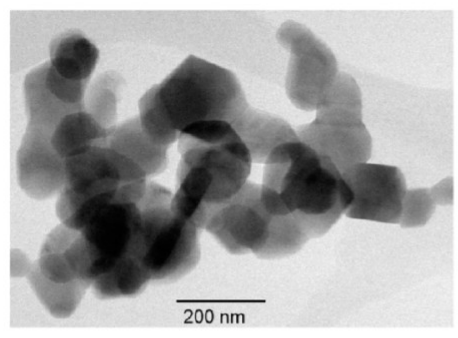

(e)

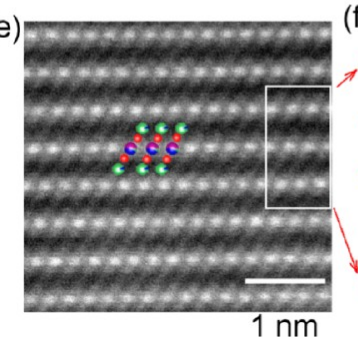

(f)

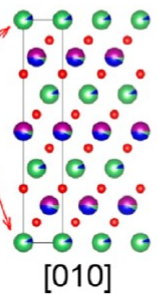

(b)

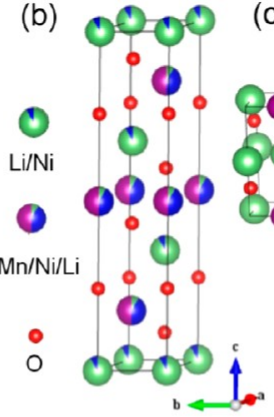

(g)

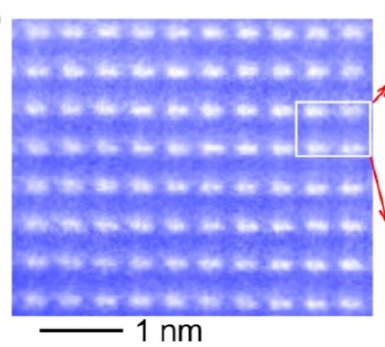

(d)

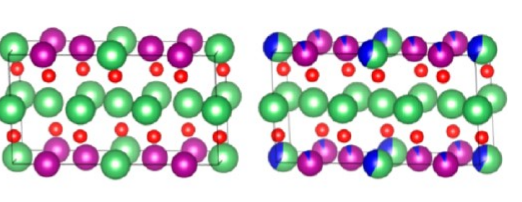

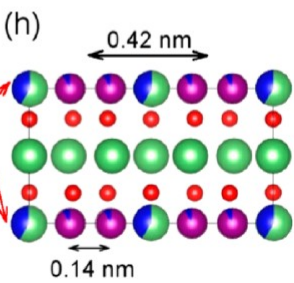

[100]

Figure 1. (a) Overview bright-field scanning transmission electron microscopy (STEM) image of the as-obtained LNMO nanoparticles. (b) Crystal model for the $\mathrm{LiMO}_{2} R \overline{3} \mathrm{~m}$ parent phase based on a $\mathrm{Li}\left(\mathrm{Mn}_{0.5} \mathrm{Ni}_{0.5}\right) \mathrm{O}_{2}$ structure with lattice parameters: $a=b=2.887 \AA, c=14.29 \AA, \alpha=\beta=90^{\circ}$, and $\gamma=120^{\circ} .{ }^{24}$ (c) Crystal model for $\mathrm{Li}_{2} \mathrm{MO}_{3} \mathrm{C} 2 / \mathrm{m}$ parent phase based on $\mathrm{Li}_{2} \mathrm{MnO}_{3}$ with lattice parameters: $a=4.926 \AA, b=8.527 \AA, c=5.028 \AA, \alpha=\gamma$ $=90^{\circ}$, and $\beta=109.22^{\circ} .{ }^{24}$ (d) Partially cation-ordered $\mathrm{Li}_{2} \mathrm{MO}_{3} \mathrm{C} 2 / \mathrm{m}$ phase based on Ni-containing $\mathrm{Li}_{2} \mathrm{MnO}_{3} .{ }^{16}$ (e) Z-contrast image of one sample region corresponding to (f) [010] zone projection of the $\mathrm{LiMO}_{2} R \overline{3} m$ model. (g) Crystal region corresponding to (h) [100] zone projection of the $\mathrm{Ni}$-doped $\mathrm{Li}_{2} \mathrm{MnO}_{3} \mathrm{C} 2 / m$ phase.
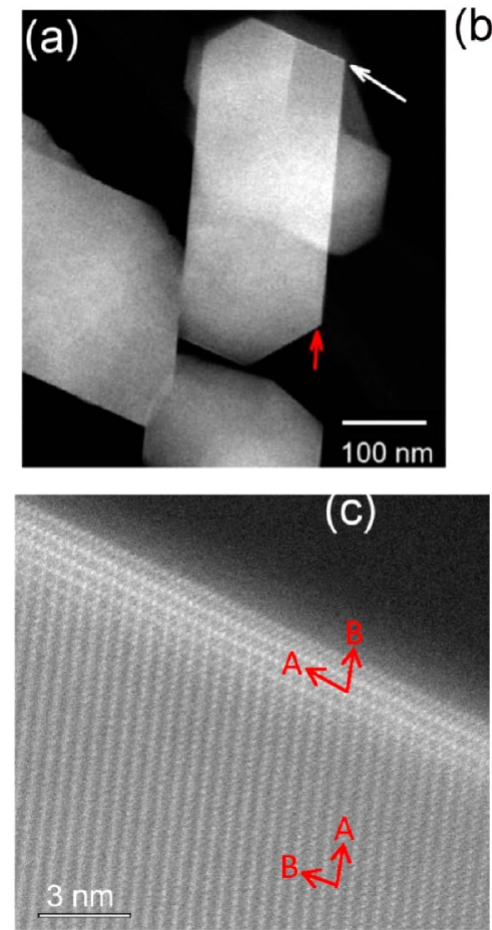

(b)
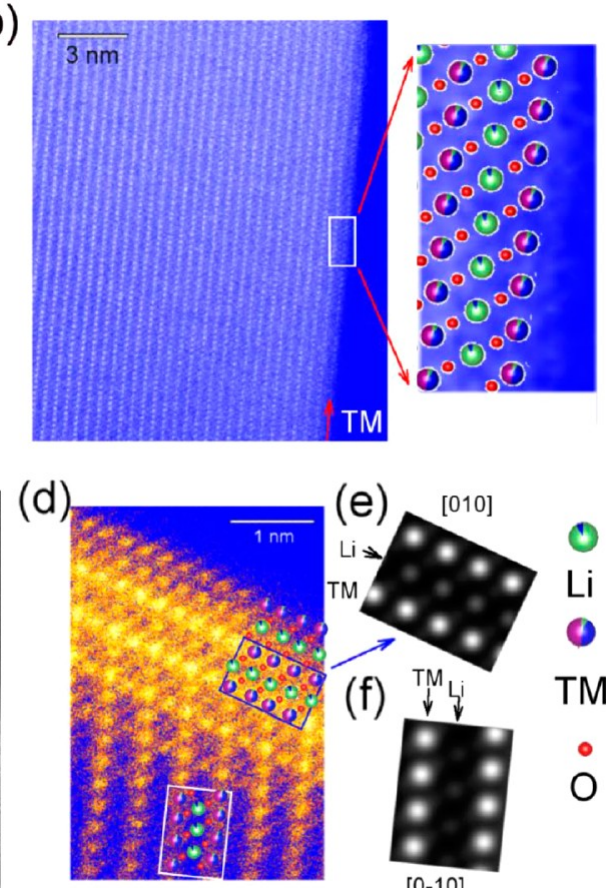

Figure 2. (a) Overview Z-contrast image of LNMO nanoparticles. (b) Atomic resolution Z-contrast image of the surface region labeled by the red arrow in (a). (c) Atomic resolution Z-contrast image of the surface region labeled by the white arrow in (a). (d) Higher magnification image of the surface layer shown in (c). (e) Simulated [010] zone projection Z-contrast image based on $\mathrm{LiNi}_{0.5} \mathrm{Mn}_{0.5} \mathrm{O}_{2}$ crystal model with $20 \% \mathrm{Ni} / \mathrm{Li}$ disorder corresponding to the region labeled with blue rectangle in (d). (f) Simulated [0-10] zone projection Z-contrast image based on $\mathrm{LiNi}_{0.5} \mathrm{Mn}_{0.5} \mathrm{O}_{2}$ crystal model with $10 \% \mathrm{Ni} / \mathrm{Li}$ disorder corresponding to the region labeled with a white rectangle in (d). TM is transition metal. Letters A and $\mathrm{B}$ in (c) marks two typical Li diffusion paths. The path $\mathrm{A}$ is a fast diffusion channel within the layer.

charge/discharge processes. ${ }^{5}$ Here we report our surprising discovery of a selective surface lattice plane segregation of nickel $(\mathrm{Ni})$ ions for the case of LNMO as a representative case for the transition-metal oxide-based cathode and the possible implications of such a surface segregation on the $\mathrm{Li}$ ion transport behavior in this category of cathode material. What we have observed is a phenomenon that is far beyond general expectation and will broadly impact the research effort for 

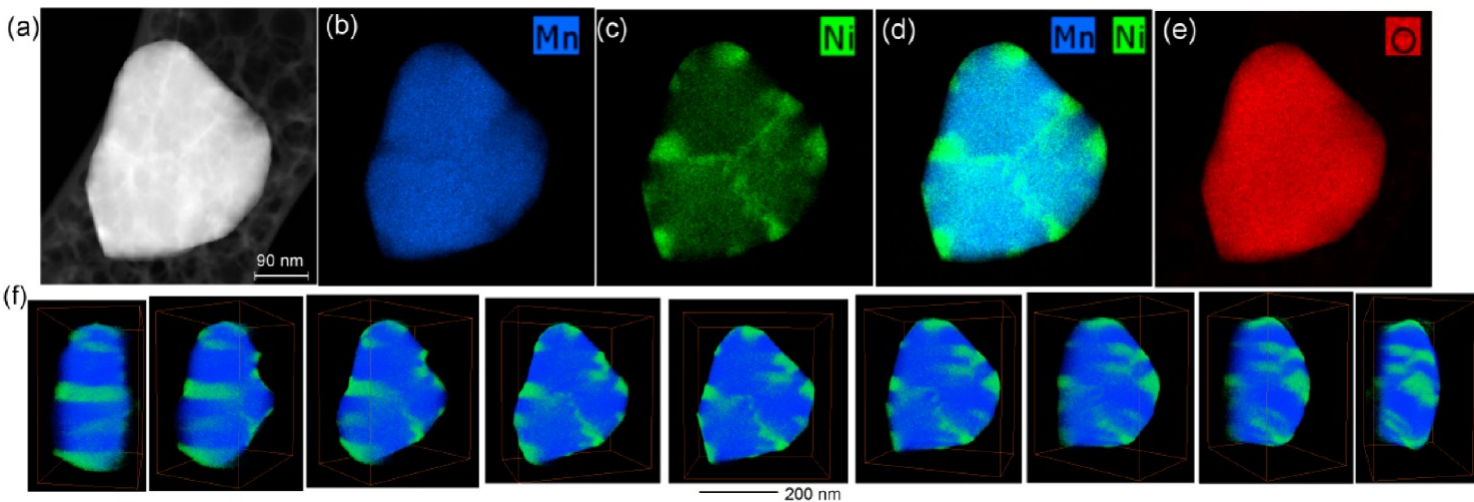

$-40$

$-20$

40

60

Figure 3. (a) Z-contrast image of a nanoparticle with internal grain boundaries and XEDS maps: (b) Mn, (c) Ni, (d) overlaid Ni and Mn, and (e) O maps (f) 3D XEDS tomography: reconstructed $\mathrm{Mn}$ and $\mathrm{Ni}$ elemental distribution maps projected at different angles showing that the Ni segregated to certain surfaces and grain boundaries.

(a)

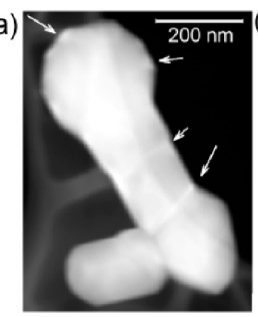

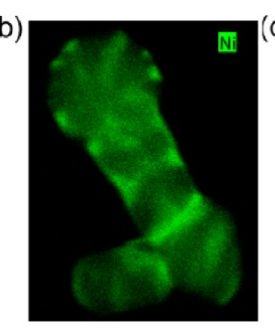

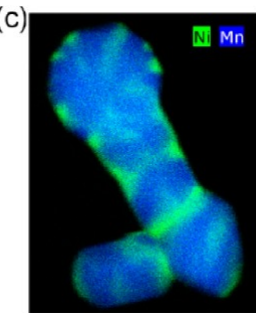

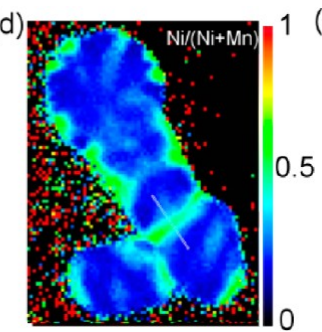

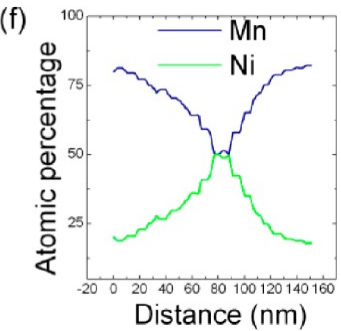

Distance $(\mathrm{nm})$

Figure 4. Z-contrast image and XEDS maps of multiple nanoparticle aggregate; (a) Z-contrast image, (b) Ni, (c) overlayed $\mathrm{Ni}$ and $\mathrm{Mn}$, and (d) Ni/ $(\mathrm{Mn}+\mathrm{Ni})$ atomic percentage quantification maps. (f) Atomic percentage of $\mathrm{Mn}$ and $\mathrm{Ni}$ along the white line in (f). The scale bar in (a) applies to all the images.

enhancing the rate performance of $\mathrm{Li}$ ion batteries and stability of cathode in the electrolyte.

As shown in the overview image in Figure 1a, the assynthesized LNMO nanoparticles assume a plate-like shape and a significant number of the particles exhibit good surface facets. As reported, LNMO structure comprises two components as shown in Figure $1 \mathrm{~b}-\mathrm{d}$ : monoclinic $\mathrm{Li}_{2} \mathrm{MO}_{3} \mathrm{C} 2 / \mathrm{m}$ and trigonal $\mathrm{LiMO}_{2} \quad R \overline{3} m\left(\alpha-\mathrm{NaFeO}_{2}\right.$ structure $)(\mathrm{M}=$ transition metal). ${ }^{11,14,23-25}$ Both phases belong to a layered structure composed of repeating transition-metal layers, oxygen layers and $\mathrm{Li}$ layers as shown in Figure $1 \mathrm{~b}-\mathrm{d}$. In the $R \overline{3} \mathrm{~m}$ structure (Figure $\mathrm{lb}$ ), $\mathrm{Ni}$ and $\mathrm{Li}$ are located at both the $3 \mathrm{a}$ and $3 \mathrm{~b}$ sites, whereas $\mathrm{Mn}$ is located only at the 3a site (using Wyckoff notation). ${ }^{24,26}$ On the other hand, in the cation ordered $\mathrm{Li}_{2} \mathrm{MO}_{3} \mathrm{C} 2 / m$ structure (Figure 1c), the larger $\mathrm{Ni}^{2+}$ cations preferably replace the $\mathrm{Li}^{+}$cations in the transition-metal layer ( $2 \mathrm{~b}$ sites) and a small portion of $\mathrm{Mn}$ cations as shown in Figure $1 d$. We found that most of the region of the particle adopts the $\alpha-\mathrm{NaFeO}_{2} R \overline{3} m$ structure in which the transition-metal layer has the highest contrast in the high angle annular dark field (HAADF) Z-contrast image in Figure 1e,f, while the oxygen layers can be clearly visualized on both sides of the transitionmetal column. Due to the much smaller atomic number of $\mathrm{Li}$, it cannot be clearly seen in the Z-contrast image Figure 1e,f. Partially ordered $\mathrm{Li}_{2} \mathrm{MO}_{3} \mathrm{C} 2 / m$ phase is also observed in part of the particle. The $\mathrm{Z}$-contrast image in Figure $1 \mathrm{~g}$ unambiguously identifies the partially cation-ordered region corresponding to the $[100]$ zone projection of the $\mathrm{Ni}$ containing $\mathrm{Li}_{2} \mathrm{MnO}_{3} \mathrm{C} 2 / \mathrm{m}$ structure model in Figure $1 \mathrm{~h}$. This structure is well-characterized by two bright Mn columns separated by $0.14 \mathrm{~nm}$ and the center of two neighboring $\mathrm{Mn} /$ $\mathrm{Ni}$ dumbbell columns spaced by $0.42 \mathrm{~nm} .^{16,23,27}$

In the Z-contrast image, we noticed that for a single particle, some faceting planes are brighter than the others as typically shown in Figure 2a, in which two facets adjacent to each other were labeled with white and red arrows. Figure $2 \mathrm{~b}$ is the atomic resolution image of the red arrowed facet, revealing that this facet corresponds to the (001) plane and is terminated at transition-metal ions. On the other hand, the white arrowed facet corresponds to the (104) plane of the particle and is characterized by a surface layer with a higher contrast than the interior of the particle as shown in Figure 2c. The higher Zcontrast of this surface layer indicates a high concentration of heavy elements, $\mathrm{Ni}\left(\mathrm{Z}_{\mathrm{Ni}}=28\right.$ compared to $\mathrm{Z}_{\mathrm{Mn}}=25$ and $\mathrm{Z}_{\mathrm{Li}}=$ 3 ) at the surface. An atomic resolution $Z$-contrast image combined with the multislice image simulations as illustrated in Figure $2 \mathrm{~d}-\mathrm{f}$ reveals that this surface layer corresponds to the [010] zone axis projection of $R \overline{3} m$ crystal structure. This surface capping layer is oriented such that the otherwise mix of cations and anions terminated (104) facet of the particle is also terminated with a transition-metal layer as is similarly the case of (001) plane. This observation clearly demonstrates that if the termination surface ends up with a transition-metal layer (such as (001) surface), there is no surface modification layer as shown by Figure $2 b$. On the other hand, if the particle surface is terminated with a mix of cations and anions, a surface capping layer is formed by preferential segregation of $\mathrm{Ni}$ ions, which eventually leads to the termination of the particle facet as transition-metal ions.

The selective surface modification associated with $\mathrm{Ni}$ segregation is consistently supported by the quantitative 
(a)

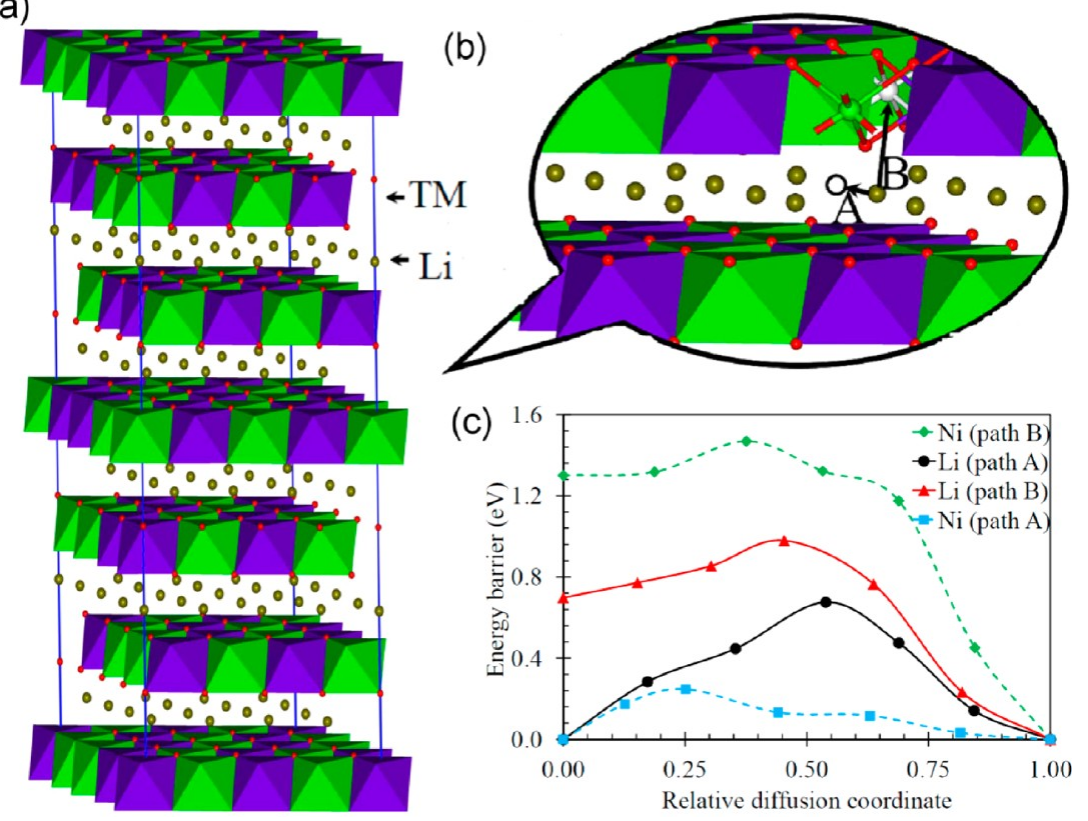

Figure 5. (a) Crystal model of the $\mathrm{LiNi}_{0.5} \mathrm{Mn}_{0.5} \mathrm{O}_{2}$ structure defined for the calculation. (b) Different diffusion paths for Li and Ni diffusion. Note that at the end of paths $\mathrm{A}$ and $\mathrm{B}$ are a $\mathrm{Li}$ and a transition-metal vacancy site. (c) Energy barrier along the diffusion paths A and B.

composition analysis using large-area X-ray energy dispersive spectroscopy (XEDS) mapping and tomography (Figures 3 and 4). The Z-contrast images at $0^{\circ}$ tilt in Figure 3a show that the grain boundaries and some surface regions exhibit an enhanced Z-contrast, implying a higher concentration of Ni. Through the integration of $\mathrm{Mn}, \mathrm{Ni}$, and $\mathrm{O} \mathrm{K}_{\alpha}$ peaks, element specific quantitative maps were obtained and are shown in Figure $3 \mathrm{~b}-\mathrm{e}$. Most surprisingly, the $\mathrm{Ni}$ distribution is extremely uneven; while rich in grain boundaries and certain surface regions, it is deficient in the interior of the particles. The average Ni:Mn ratio is $1: 3$ as quantified using peak integrated XEDS spectra of the whole particle, which corresponds well to the $\mathrm{Ni}: \mathrm{Mn}$ ratio in the nomnal composition $\mathrm{Li}_{1.2} \mathrm{Ni}_{0.2} \mathrm{Mn}_{0.6} \mathrm{O}_{2}$. A series of XEDS maps were also acquired at $5^{\circ}$ tilt increments from $-70^{\circ}$ to $+70^{\circ}$ and reconstructed to provide a $3 \mathrm{D}$ visualization of the $\mathrm{Ni}$ and $\mathrm{Mn}$ distribution in the LNMO nanoparticle. The 3D morphological structure and the spatial distribution of the segregated $\mathrm{Ni}$ of a single LNMO particle are illustrated by the overlaid $\mathrm{Mn}$ and $\mathrm{Ni}$ maps projected at different tilt angles of the reconstructed LNMO nanoparticle (Figure 3f). The animated $3 \mathrm{D}$ visualization of the chemical mapping of the nanoparticle is in the Supporting Information movie. It reveals that the Ni ions are selectively segregated at certain surface locations and grain boundaries. This is further supported by the XEDS chemical analysis in a region with several nanoparticle aggregates as illustrated in Figure 4. The XEDS quantification reveals that the $\mathrm{Ni} / \mathrm{Mn}$ ratio ranges from $\sim 1: 4$ inside the particle to $\sim 1: 1$ in certain surfaces or grain boundaries in Figure $4 \mathrm{f}$. It should be pointed out that $\mathrm{Xu}$ et al. ${ }^{28}$ have studied the surface structure of the LNMO particle following the charge/discharge cycles. They noticed that a surface layer was formed on the particle due to substitution of $\mathrm{Li}$ ions by transition metal cations and formation of spinal structure. As we are focusing on the freshly prepared sample, we do not see any formation of spinel at the surface region of the particles.

What we have observed in this work contrasts markedly with the general observation of other multicomponent nanoparticles for which the segregating species tend to uniformly cover the whole nanoparticle surface, leading to a core-shell structure. $^{29,30}$ This interesting selective surface modification phenomenon is related to the surface energies of different terminations and the diffusion kinetics of $\mathrm{Ni}$ cations within the layered structure. As calculated by Wei et al., ${ }^{8}$ for a similar composition crystal, $\mathrm{Li}\left[\mathrm{Li}_{0.17} \mathrm{Ni}_{0.25} \mathrm{Mn}_{0.58}\right] \mathrm{O}_{2}$, the (001), a surface ending with a transition-metal layer has a lower surface energy and, therefore, is thermodynamically more stable. On the other hand, the surfaces ending with alternating transitionmetal, oxygen, and Li layers are not thermodynamically stable. We used DFT to calculate the diffusion energy barriers of $\mathrm{Li}^{+}$ across different paths. It should be pointed out that the diffusion energy barrier shows dependence on diffusion mechanisms and overall elemental composition. For example, $\mathrm{Li}$ diffusion in layered intercalation compounds, such as $\mathrm{Li}_{x} \mathrm{CoO}_{2}$ and $\mathrm{Li}_{x} \mathrm{TiS}_{2}$, is a divacancy-mediated mechanism. ${ }^{31-33}$

Here, the calculation is based on the $\mathrm{LiNi}_{0.5} \mathrm{Mn}_{0.5} \mathrm{O}_{2} R \overline{3} m$ model as shown in Figure 5a (details of the calculations are described in the Supporting Information). Two different paths are considered for Li migration in this layered structure through cation vacancy migration, as shown in Figure $5 \mathrm{~b}$. Path $\mathrm{A}$ is parallel to the $\mathrm{Li}^{+}$layer involving an in-plane jump from the start site to the nearby vacancy site in the $\mathrm{Li}^{+}$layer. $\mathrm{As} \mathrm{Li}^{+}$can also reside at the transition-metal layer, the jump from $\mathrm{Li}$ site to a $\mathrm{Ni}$ vacancy is also considered, which indicates an off-plane jump (path B). In Figure 2c, these two possible Li diffusion paths $A$ and $B$ are labeled with arrows in the bulk crystal and surface layers. Those two diffusion paths are also considered for $\mathrm{Ni}$ migration. As $\mathrm{Li}$ or $\mathrm{Ni}$ ions move from one octahedral site to another, it will pass through an intermediate tetrahedral site where it encounters the repulsion from a nearby transitionmetal cation. The energy barrier for $\mathrm{Ni}$ or Li diffusion should be related to the different degrees of repulsion from the transitionmetal cation. As shown in Figure 5c, the energy barriers for both $\mathrm{Li}$ and $\mathrm{Ni}$ diffusion along path $\mathrm{A}$ are much lower than path $\mathrm{B}$, consistent with previous models for diffusion in this system. 
The calculation in Figure 5c shows that the energy barrier for $\mathrm{Ni}$ to diffuse along the $\mathrm{Li}$ channel is $\sim 0.25 \mathrm{eV}$; therefore, it is very easy for $\mathrm{Ni}$ to diffuse to the surface once $\mathrm{Ni}$ is in the $\mathrm{Li}^{+}$ layer. In contrast, the diffusion energy barrier for $\mathrm{Ni}$ to diffuse along path $\mathrm{B}$ is as high as $1.47 \mathrm{eV}$, implying that $\mathrm{Ni}$ is not very likely to diffuse along path B. Similarly, the diffusion barrier for $\mathrm{Li}^{+}$along path A parallel with the $\mathrm{Li}^{+}$layer is around $0.67 \mathrm{eV}$ compared to $0.98 \mathrm{eV}$ along path $\mathrm{B}$. This result corresponds well with earlier reports regarding to the $\mathrm{Li}^{+}$fast diffusion paths. ${ }^{34}$ Most importantly, the diffusion barrier for $\mathrm{Ni}$ along the $\mathrm{Li}^{+}$ layer is smaller than $\mathrm{Li}^{+}$, implying that $\mathrm{Ni}$ diffusion along the $\mathrm{Li}^{+}$ channels is even easier. Taken together, these results explain the experimentally observed selective $\mathrm{Ni}$ segregation and corresponding surface modification phenomenon described above in Figures 2 and 3.

The charge/discharge rate of a cathode material is critically controlled by the Li ion mobility in the lattice. Theoretical calculations and experimental observation have established that in the layer structured cathode, $\mathrm{Li}$ ion diffusion along the layer is much easier than across the layer. ${ }^{5,28,31-33}$ The channels within the surface layer formed on the nanoparticle are approximately perpendicular to the channels inside the particle (relative rotation angle of $\sim 109.5^{\circ}$ ). Therefore, the formation of the surface layer should lead to a diffusion barrier for $\mathrm{Li}$ at the particle surface region. Consequently, from all we know of the mechanism of charging/discharging, this surface layer should affect the charge/discharge rate of the battery. Of course, to quantify this link, more systematic experimental work should be performed to examine the effect of nanoscale chemical inhomogeneities and structural variations within a single particle on the overall battery performance. The present observations clearly indicate that this Ni surface modification phenomenon can occur during material synthesis. As cation diffusion is highly related to the synthesis temperature and high-temperature growth time, optimizing these material processing parameters may decrease the level the segregation related surface layer. Several approaches were employed in this study (sol-gel, hydrothermal, and coprecipitation) that incorporated a wide variation in the synthesis conditions for the LNMO system. All the LNMO synthesized for our analysis showed some degree of $\mathrm{Ni}$ segregation. In a typical example, we mixed $\mathrm{Ni}_{0.25} \mathrm{Mn}_{0.75}(\mathrm{OH})_{2}$ and $\mathrm{Li}_{2} \mathrm{CO}_{3}$, and the mixture was calcined at $900{ }^{\circ} \mathrm{C}$ for different times. Microscopically, we found that with a longer calcination time, the particles are prone to possess well-defined facets and show Ni segregations. The charge/discharge rate of batteries using these materials shows a dependence on the calcination time of the LNMO particles: the longer of the calcination time, the poorer the rate performance. It should be noted that the poor rate for the particles with a longer calcination time is also related to the large particle size. Clarification of the exact roles of surface segregation and particle size on the rate of the battery performance will be the focus of future work. Further and more broadly, this surface modification phenomenon may also be present in other composite cathode materials and may alter the $\mathrm{Li}$ ion diffusion channels. Therefore, the present observation of selective surface segregation will impact the general approach for tailoring cathode structures for a high capacity and a high power rate.

\section{ASSOCIATED CONTENT}

\section{Supporting Information}

Supporting movie, synthesis procedure of LNMO nanoparticles, experimental procedure for the STEM XEDS mapping and tomographic reconstruction, multislice STEM image simulations, and DFT calculation of $\mathrm{Li}^{+}$diffusion energy barrier. This material is available free of charge via the Internet at http://pubs.acs.org

\section{AUTHOR INFORMATION}

\section{Corresponding Author}

*E-mail: Chongmin.Wang@pnnl.gov

Notes

The authors declare no competing financial interest.

\section{ACKNOWLEDGMENTS}

M.G. wants to thank Dr. Chengyu Song from NCEM for technical support on the TEAM 0.5 microscope and Dr. Paul Plachinda from the FEI Company for his help on 3D XEDS data processing and visualization. This work was supported by the Laboratory Directed Research and Development (LDRD) program of Pacific Northwest National Laboratory (PNNL). The work was conducted in the William R. Wiley Environmental Molecular Sciences Laboratory (EMSL), a national scientific user facility sponsored by DOE's Office of Biological and Environmental Research and located at PNNL. PNNL is operated by Battelle for the DOE under contract DE-AC0576RLO1830. Part of the work performed at NCEM is supported by DOE under contract no. DE-AC02-05CH11231.

\section{REFERENCES}

(1) Kang, B.; Ceder, G. Nature 2009, 458, 190

(2) Chiang, Y.-M. Science 2010, 330, 1485.

(3) Tarascon, J. M.; Armand, M. Nature 2001, 414, 359.

(4) Kang, K.; Morgan, D.; Ceder, G. Phys. Rev. B 2009, 79, 014305.

(5) Nishimura, S.-I.; Kobayashi, G.; Ohoyama, K.; Kanno, R.; Yashima, M.; Yamada, A. Nat. Mater. 2008, 7, 707.

(6) Chung, S.-Y.; Bloking, J. T.; Chiang, Y.-M. Nat. Mater. 2002, 1, 123

(7) Delacourt, C.; Poizot, P.; Levasseur, S.; Masquelier, C. Electrochem. Solid-State Lett. 2006, 9, A352.

(8) Wei, G.-Z.; Lu, X.; Ke, F.-S.; Huang, L.; Li, J.-T.; Wang, Z.-X.; Zhou, Z.-Y.; Sun, S.-G. Adv. Mater. 2010, 22, 4364.

(9) Hinuma, Y.; Meng, Y. S.; Kang, K.; Ceder, G. Chem. Mater. 2007, 19, 1790.

(10) Reed, J.; Ceder, G. Electrochem. Solid-State Lett. 2002, 5, A145.

(11) Lu, Z.; Beaulieu, L. Y.; Donaberger, R. A.; Thomas, C. L.; Dahn, J. R. J. Electrochem. Soc. 2002, 149, A778.

(12) Wang, J.; Yao, X.; Zhou, X.; Liu, Z. J. Mater. Chem. 2011, 21, 2544.

(13) Peng, Q.; Tang, Z.; Zhang, L.; Liu, X. Mater. Res. Bull. 2009, 44, 2147.

(14) Armstrong, A. R.; Holzapfel, M.; Novák, P.; Johnson, C. S.; Kang, S.-H.; Thackeray, M. M.; Bruce, P. G. J. Am. Chem. Soc. 2006, $128,8694$.

(15) Hong, J.; Seo, D.-H.; Kim, S.-W.; Gwon, H.; Oh, S.-T.; Kang, K. J. Mater. Chem. 2010, 20, 10179.

(16) Jarvis, K. A.; Deng, Z.-Q.; Allard, L. F.; Manthiram, A.; Ferreira, P. J. Chem. Mater. 2011, 23, 3614.

(17) Wang, J.; Xia, Y.; Yao, X.; Zhang, M.; Zhang, Y.; Liu, Z. Int. J. Electrochem. Sci. 2011, 6, 6670.

(18) Hong, Y.-S.; Park, Y. J.; Ryu, K. S.; Chang, S. H.; Kim, M. G. J. Mater. Chem. 2004, 14, 1424.

(19) Zhang, L.; Zhang, Z. C.; Wu, H. M.; Amine, K. Energy Environ. Sci. 2011, 4, 2858. 
(20) Sun, Y. K.; Myung, S. T.; Park, B. C.; Prakash, J.; Belharouak, I.; Amine, K. Nat. Mater. 2009, 8, 320.

(21) Thackeray, M. M. J. Am. Ceram. Soc. 1999, 82, 3347.

(22) Johnson, C. S.; Kim, J. S.; Lefief, C.; Li, N.; Vaughey, J. T.; Thackeray, M. M. Electrochem. Commun. 2004, 6, 1085.

(23) Bareño, J.; Lei, C. H.; Wen, J. G.; Kang, S. H.; Petrov, I.; Abraham, D. P. Adv. Mater. 2010, 22, 1122.

(24) Meng, Y. S.; Ceder, G.; Grey, C. P.; Yoon, W. S.; Jiang, M.; Breger, J.; Shao-Horn, Y. Chem. Mater. 2005, 17, 2386.

(25) Lei, C. H.; Bareno, J.; Wen, J. G.; Petrov, I.; Kang, S. H.; Abraham, D. P. J. Power Sources 2008, 178, 422.

(26) Islam, M. S.; Davies, R. A.; Gale, J. D. Chem. Mater. 2003, 15, 4280.

(27) Strobel, P.; Lambert-Andron, B. J. Solid State Chem. 1988, 75, 90.

(28) Xu, B.; Fell, C. R; Chi, M. F.; Meng, Y. S. Energy Environ. Sci. 2011, 4, 2223.

(29) Wang, X. Y.; Ren, X. F.; Kahen, K.; Hahn, M. A.; Rajeswaran, M.; Maccagnano-Zacher, S.; Silcox, J.; Cragg, G. E.; Efros, A. L.; Krauss, T. D. Nature 2009, 459, 686.

(30) Skumryev, V.; Stoyanov, S.; Zhang, Y.; Hadjipanayis, G.; Givord, D.; Nogués, J. Nature 2003, 423, 850.

(31) Van der Ven, A.; Ceder, G. J. Power Sources 2001, 97-98, 529.

(32) Van der Ven, A.; Ceder, G.; Asta, M.; Tepesch, P. D. Phys. Rev. B 2001, 64, 184307.

(33) Van der Ven, A.; Thomas, J. C.; Xu, Q.; Swoboda, B.; Morgan, D. Phys. Rev. B 2008, 78, 104306.

(34) Islam, M. S.; Driscoll, D. J.; Fisher, C. A. J.; Slater, P. R. Chem. Mater. 2005, 17, 5085. 